\title{
Flaw evaluation of cast stainless steel pipe for revision of JSME rules on fitness for service
}

\author{
Kiminobu HOJO*, Mayumi OCHI**, Naoki OGAWA**, Shotaro HAYASHI**, \\ Wataru NISHI* and Takahisa YAMANE* \\ * Mitsubishi Heavy Industries, Ltd. \\ 1-1 Wadasaki-cho 1-chome, Hyogo-ku, Kobe 652-8585, Japan \\ E-mail: kiminobu_hojo@mhi.co.jp \\ ** Mitsubishi Heavy Industries, Ltd. \\ 1-1 Shinhama Arai-cho 2-chome, Takasago 676-8686, Japan
}

Received: 28 November 2016; Revised: 10 July 2017; Accepted: 23 July 2017

\begin{abstract}
The current JSME rules on Fitness-for-Service only applies the Elastic Plastic Fracture Mechanics (EPFM) method, including the two-parameters method for flaw evaluation of cast stainless steel (CASS) pipes, while plastic collapse is expected to occur in the case of low ferrite content or low thermal aging condition. The EPFM method of the JSME rules introduces Z-factor for simplification similar to ASME Sec. XI. The Z-factor equation for CASS pipe was derived with the assumption of a penetrated circumferential flaw, $20 \%$ ferrite content, J-R curve of fully aged material, and stress-strain (S-S) curve of unaged material, which are very conservative conditions. In order to revise the current JSME rules for a more practical and accurate flaw evaluation of CASS pipe, this paper introduced to the rules, a limit load method for low ferrite content or low thermal aging condition, and prediction models of S-S and J-R curves for thermal aging. These were verified by fracture tests using flat plate specimens with a surface flaw and detailed FE analyses. Also applicability of a Z-factor equation for an axial flaw was proposed by other authors. This paper is a technical basis for the code revision of the JSME rules.
\end{abstract}

Key words : Cast stainless steel, Net section criterion, Limit load, Ductile fracture, J-integral, Two-parameters method, J-T criterion, Allowable flaw, Rules on fitness-for-service, J-R curve, Thermal aging, EPFM, Z-factor

\section{Nomenclature}

CASS: cast stainless steel

DCGL: ductile crack growth line

EDM: Electronic discharge machining

EPC: electric potential change

EPFM: elastic plastic fracture mechanics

FAC: failure assessment curve of two parameter method

FAD: failure assessment diagram

FC: ferrite content

FE, FEA: finite element, finite element analysis

FFS: fitness for service

JSME: The Japan Society of Mechanical Engineers

ISI: in-service inspection

LL: limit load

NDI: non-destructive inspection

NSC: net section criteria

R-O: Ramberg-Osgood approximation

$\mathrm{SC}$ : screening criteria 
SMAW: sealed metal arc welding

SS: stainless steel

S-S curve: stress-strain curve

$a$ : flaw depth

$c$ : half flaw length

$C O D$ : crack opening displacement

$D_{o}$ : outer diameter

$E$ : Young's modulus

$J$ : J-integral

$J_{e}$ : elastic part of $J$

$J_{Q}: J$ at ductile crack initiation in accordance with ASTM E813-89

$J_{R}$ : J-fracture resistance

$K_{r}$ and $S_{r}$ : parameters of FAC of two-parameters method

$K_{r}$ ' and $S_{r}{ }^{\prime}$ : parameters of DCGL of two-parameters method

$K$ : stress intensity factor

$l$ : total flaw length

$p$ : pressure

$P$ : applied load

$P_{m}$ : membrane stress

$P(t, T)$ : aging parameter

$R$ : stress ratio

$R_{i}$ : inner radius

$R_{a v}$ : average radius

$S C: K_{r}{ }^{\prime} / S_{r}{ }^{\prime}$

$S_{r \text { cutoff: }}$ Cutoff of $S_{r}$

$t$ : thickness

$T$ :temperature

$\Delta a$ : crack growth amount

$\sigma:$ applied stress

$\sigma_{b}$ : bending stress

$\sigma_{c}$ : critical fracture stress

$\sigma_{m}$ : membrane stress

$\sigma_{f}$ : flow stress

$\sigma_{y}:$ yield stress, or $0.2 \%$ proof strength

$\sigma_{B}$ : tensile strength

$v$ : Poisson's ratio

\section{Introduction}

For in-service nuclear power plants in Japan, plant integrity is assured by the JSME Rules on Fitness-for-Service for Nuclear Power Plants. The first edition was published in 2000 and the revised editions have been issued every four years. The latest version is the 2016 edition. It provides flaw acceptance rules for flaw evaluation of austenitic stainless steel pipe including CASS, ferritic steel vessel and pipe. Pipe flaw evaluation is based on the LL method and elastic plastic fracture mechanics method. Since forged austenitic stainless steel has good ductility, the LL method is applied for a flawed pipe after detection of indications by ISI. Ferritic steel has a wide-range fracture toughness, and the LL method or the EPFM method for flaw evaluation of ferritic steel pipe is selected by a screening criterion considering tensile strength and fracture toughness. Two kinds of the EPFM methods in the JSME rules for FFS are provided, one is the Z-factor method (Wilkowski et al., 1989) and the other is the two-parameters method (Ainsworth et al., 1986). Both of the methods are also provided in the ASME Section XI 2015 ed. The Z-factor method is a simplified method and the Z-factor is defined by the ratio of LL to ductile instability load by the EPFM method with J-T criterion or the two-parameters method, and is normally provided by a closed-form equation using parameters such as flaw direction, pipe diameter and flaw shape, depending on the required accuracy and convenience. The so-called two-parameters 
method was developed by Ainsworth, et al. This method uses two kinds of parameters $K_{r}$ and $S_{r}$ relating to fracture mechanics and mechanics of materials, and is fundamentally equivalent to the J-T criterion for evaluation of ductile instability. The most remarkable feature is the applicability from brittle fracture to plastic collapse in one diagram.

Since CASS is susceptible to thermal aging and loses ductility after long term operation, the current JSME rules only permit the EPFM method under conservative assumption - fully aged condition, that is, the Z-factor approach or the two-parameters method as described above. The Z-factor equation for a CASS pipe of the JSME rules was formulated a few decades ago (Koyama, et al, 1999 and Hojo and Koyama, 2009) for a pipe with a circumferential flaw only, and no equation for a pipe with an axial flaw is provided. On the other hand, thermal aging effect of CASS depends on ferrite content and thermal aging condition. When CASS contains a small amount of ferrite content or it is exposed to low thermal aging condition, the fracture mode should be plastic collapse. In this case, the LL method can be applied. Because the LL method is much easier than the two-parameters method, it will be convenient for the users to introduce this method for an axial flaw. Furthermore, the current Z-factor equation is based on the EPFM analysis using the simplified $J$ equation (Kumar, et al., 1981) for a pipe with a circumferentially through-wall flaw subjected to bending and a very conservative combination of unaged S-S curve and fully aged J-R curve for high ferrite content, using the most conservative crack angle. As a result the current Z-factor equation for a circumferential flaw has a large margin. If a thermal degradation model with material properties depending on ferrite content and aging condition is introduced, the two-parameters method can reduce this excessive margin using the predicted material properties.

From the above background, the authors took measures to resolve the following three technical problems. First, tensile fracture tests of low and high ferrite CASS using flat plates with a surface flaw were performed to confirm the fracture behavior and demonstrate that plastic collapse occurs in the condition of low ferrite content, even in fully thermal aging condition. At the same time, applicability of a new fracture criterion for plastic collapse was verified for a shallow flaw. Second, the degradation model presented by Kawaguchi et al., 1997, 2005 was reinvestigated and a revision of the prediction method for S-S curve was made to improve the prediction accuracy of the curve. Third, the Z-factor for a pipe with an axial flaw by Kamaya et al. 2016 was introduced and verified by comparison with FEA results.

Based on these results, the flaw evaluation for CASS pipe in arbitrary aging condition has been established and a draft revision of the fracture analysis method for CASS pipe was proposed to the JSME committee of Codes and Standards. This is a technical background paper for the code revision of the JSME rules.

\section{Verification test for fracture behavior of CASS using flat plates with a surface flaw}

Since detailed information of the material test and fracture test was published in Hojo, et al. 2015, a summary is described here.

\subsection{Test conditions}

Seven tests were conducted. The test matrix is shown in Table 1. Material was JIS G 5121 SCS14A base metal (corresponding to $\mathrm{CF} 8 \mathrm{M}$ ) produced by static casting. The specimen A7 has a welding joint that is parallel to the tensile direction. Before the tests all specimens except A5 were exposed to a thermal aging condition of $465^{\circ} \mathrm{C}-5000 \mathrm{~h}$ which is close to fully saturated condition.

Table 1 Fracture test matrix using flat plate specimens

\begin{tabular}{cccccccc}
\hline Specimen & Base/Weld & Ferrite content $(\%)$ & $a(\mathrm{~mm})$ & $l(\mathrm{~mm})$ & $a / t$ & $a / l$ & Aged/Unaged \\
\hline A1 & Base & 9.3 & 2.4 & 37.8 & 0.096 & 0.064 & Aged \\
A2 & Base & 9.3 & 5.4 & 36.7 & 0.22 & 0.15 & Aged \\
A3 & Base & 9.7 & 12.0 & 36.4 & 0.48 & 0.33 & Aged \\
A4 & Base & 9.7 & 17.0 & 28.9 & 0.68 & 0.59 & Aged \\
A5 & Base & 10.5 & 7.6 & 39.3 & 0.30 & 0.19 & Unaged \\
A6 & Base & 18.9 & 12.0 & 38.3 & 0.48 & 0.31 & Aged \\
A7 & Weld & 18.9 & 13.0 & 39.3 & 0.52 & 0.33 & Aged \\
\hline
\end{tabular}

The specimen shape is shown in Fig.1. At the center of the specimen an EDM notch was produced and a fatigue crack was introduced afterwards by cyclic tensile or bending load. The weld joint specimen A7 was produced by SMAW simulating the actual welding material NC-36LK, welding condition and the geometry of a weld joint groove. 
Figure 2 shows an image of the specimen A7.

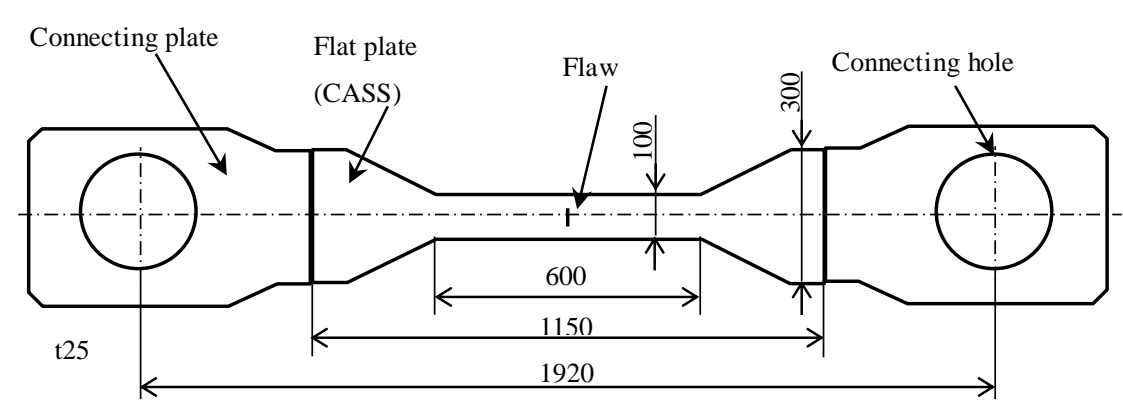

Fig. 1 Flat plate specimen

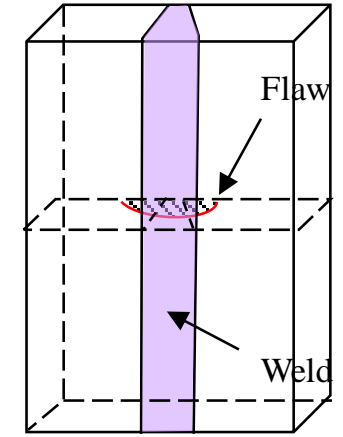

Fig. 2 Image of speicmenA7

The items measured were applied load (by load cell), COD (clip gauge), displacement between pins (displacement gauge), crack depth (electric potential method), temperature (thermo-couple), and deformation (video). The temperature was kept at $325^{\circ} \mathrm{C}$ during the test by using heater and insulating material.

\subsection{Test result}

Table 2 shows a summary of the fracture tests.

The following were observed.

- The maximum loads for A3 (low ferrite) and A6 (high ferrite) with the same size flaws are nearly equal and within a $2 \%$ erence.

- The maximum loads for A2 (aged) and A5 (unaged) with a similar size flaw are nearly equal and within a $2 \%$ difference.

- On the other hand, the maximum CODs compared in the same manner as above are quite different (two times or more) (for example, Fig. 3 and Fig. 4).

- The effects due to the difference of the materials and the residual stress by welding are negligible based on the results of $\mathrm{A} 6$ and $\mathrm{A} 7$.

Table 2 Summary of fracture tests

\begin{tabular}{|c|c|c|c|c|c|c|}
\hline \multirow{2}{*}{ Specimen } & \multirow{2}{*}{$\begin{array}{c}\text { Ferrite } \\
\text { content }(\%)\end{array}$} & \multicolumn{3}{|c|}{ Conditions } & \multirow{2}{*}{$\begin{array}{c}\text { Max. load } \\
(\mathrm{kN})\end{array}$} & \multirow{2}{*}{$\begin{array}{l}\text { Max. } C O D \\
(\mathrm{~mm})\end{array}$} \\
\hline & & Material & Aged/Unaged & $a / t$ & & \\
\hline A1 & \multirow{5}{*}{$\begin{array}{l}\text { Low } \\
(10 \%)\end{array}$} & \multirow{5}{*}{ Base } & \multirow{4}{*}{ Aged } & 0.096 & 1035 & 4.7 \\
\hline $\mathrm{A} 2$ & & & & 0.22 & 878 & 5.3 \\
\hline A3 & & & & 0.48 & 771 & 6.9 \\
\hline A4 & & & & 0.68 & 712 & 6.5 \\
\hline A5 & & & Unaged & 0.30 & 897 & 10.4 \\
\hline A6 & \multirow{2}{*}{$\begin{array}{l}\text { High } \\
(19 \%)\end{array}$} & Base & \multirow{2}{*}{ Aged } & 0.48 & 787 & 2.4 \\
\hline A7 & & Weld & & 0.52 & 779 & 2.0 \\
\hline
\end{tabular}

From these observations, thermal aging and ferrite content affect the fracture mode, plastic collapse or ductile fracture, but do not affect the maximum load or stress greatly in these cases. 


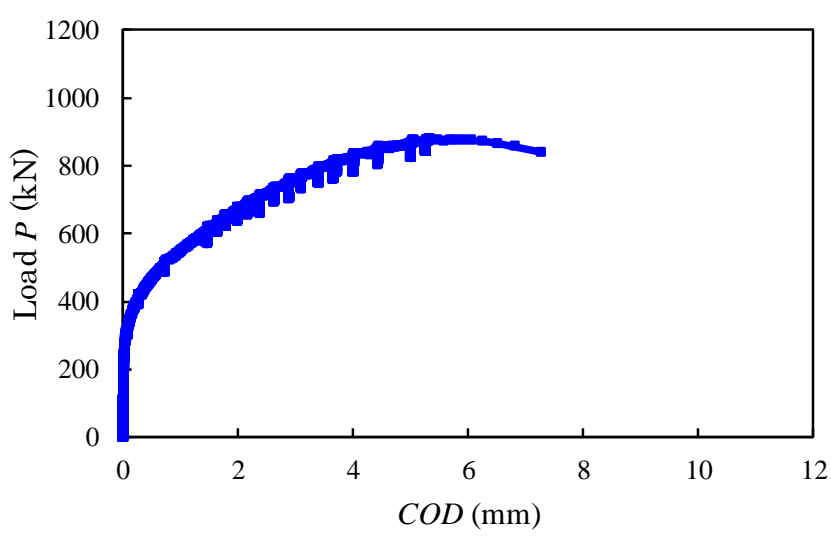

Fig. 3 Load-COD curve (Specimen A2)

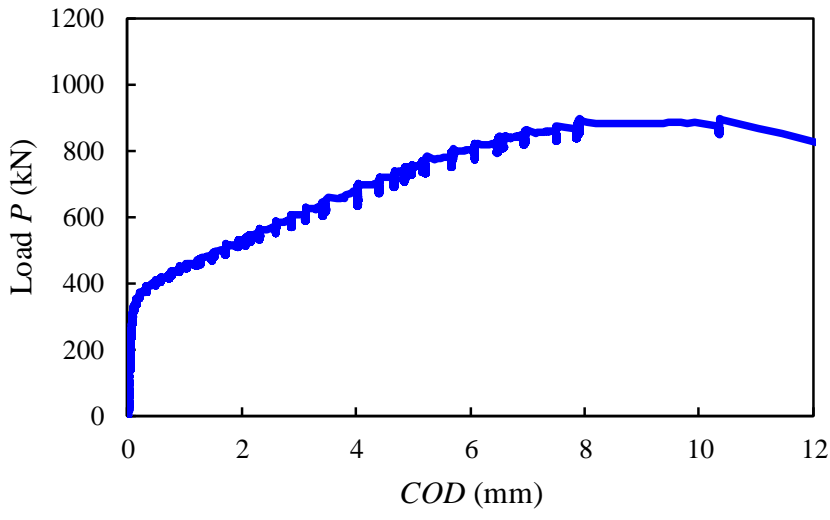

Fig. 4 Load-COD curve (Specimen A5)

\subsection{Analysis of fracture test}

In order to predict the maximum load, the LL method and two-parameters method using the analytical evaluation method provided by the JSME rules on FFS were applied. Since these methods of JSME rules on FFS are for a pipe, the calculation was modified for a flat plate. FE analysis was conducted because $J$ calculation was required for the two-parameters method.

\subsubsection{Analysis condition}

\section{(1) Analysis method}

The analysis procedures for the fracture modes of plastic collapse and ductile fracture were chosen for the flat plate tests with a surface flaw.

\section{a. LL method}

Sattari-Far, et al., 2004 provides $S_{r}$ as a parameter of the horizontal axis of the two-parameters method for a flat plate with a surface flaw as shown below.

$$
S_{r}=\frac{(1-\zeta)^{1.58} \frac{\sigma_{b}}{3}+\sqrt{(1-\zeta)^{3.16} \frac{\sigma_{b}^{2}}{9}+(1-\zeta)^{3.14} \sigma_{m}^{2}}}{(1-\zeta)^{2} \sigma_{y}}
$$

Here,

$$
\zeta=\frac{a l}{t(l+2 t)}
$$

When $\sigma_{y}$ is replaced with $\sigma_{f}$ and $S_{r}=1$, Eq. (1) can provide LL at plastic collapse of a flawed structure. $\sigma_{f}$ is normally defined by the average of $\sigma_{y}$ and $\sigma_{B}$. As $\sigma_{m}$ was dominant for the fracture tests in this research, $\sigma_{b}$ was set to 0 . Therefore the applied $\sigma_{m}$ at plastic collapse is given by Eq. (3)

$$
\sigma_{m}=\sigma_{f}(1-\zeta)^{0.43}
$$

In case of a shallow flaw, the Code Case of Nuclear Power Generation Facilities provides the critical fracture stress $\sigma_{c}$ depending on the axial flaw depth that is less than or equal to $0.5 t$ instead of $\sigma_{f}$. The expression of $\sigma_{c}$ is shown below.

$$
\sigma_{c}=\left\{\begin{array}{lc}
\sigma_{B} & 0 \leq a / t<0.1 \\
\frac{1}{0.16}\left(\sigma_{B}-\sigma_{f}\right)(0.5-a / t)^{2}+\sigma_{f} & 0.1 \leq a / t \leq 0.5 \\
\sigma_{f} & 0.5<a / t \leq 1.0
\end{array}\right.
$$

LL using $\sigma_{c}$ was calculated for plastic collapse.

b. Two-parameters method

As described in the first chapter, the two-parameters method evaluates the fracture behavior using two parameters 
$K_{r}$ and $S_{r}$ relating to fracture mechanics and mechanics of materials. $K_{r}$ and $S_{r}$ are basically defined by $K_{I} / K_{I c}$ and $\sigma / \sigma_{y}$, respectively. In the original two-parameters method, the FAC of the Dugdale model was derived using a relation of $K_{r}$ and $S_{r}$. FAC is a trajectory of $K_{r}$ and $S_{r}$ along increase of applied load or stress without crack extension. For a fracture mode of ductile crack extension, FAC is expressed using the J-integral and expressions for a flat plate with a surface flaw were determined in accordance with the definitions of $S_{r}$ and $K_{r}$, as shown in Eq. (5)-(7).

$$
\begin{aligned}
& S_{r}=\frac{\sigma_{m}}{(1-\zeta)^{0.43} \sigma_{y}} \\
& K_{r}=\sqrt{\frac{J_{e}}{J}}
\end{aligned}
$$

Here,

$$
J_{e}=\frac{K^{2}\left(1-v^{2}\right)}{E}
$$

$K$ in Eq. (7) was calculated using the $K$ equation for a semi-elliptical surface flaw of a plate, as described in Appendix E-5 of the JSME rules on FFS, and by fixing the flaw shape and changing the applied load. $J$ was calculated directly by FEA in a similar manner to $K$. $S_{r \text { cutoff }}$ is determined by $\sigma_{f} / \sigma_{y}$.

DCGL is a trajectory of $K_{r}$ and $S_{r}$ with crack extension under fixed applied load or stress. The DCGL of a flat plate with a surface flaw was determined in accordance with the definition of $S_{r}$ ' using the same equations (5), and $K_{r}$ ' shown in Eq. (8) with fixed loads and continuing crack growth until $a / t=0.8$. Aspect ratio of the flaw was fixed.

$$
K_{r}{ }^{\prime}=\sqrt{\frac{J_{e}}{J_{R}}}
$$

\section{(2) Material data}

Specimens for the material tests were taken from the material for the flat plate specimens. They were exposed to the same thermal aging condition as the flat test specimens. Material properties at $325^{\circ} \mathrm{C}$ are shown in Table 3 . The S-S curve for each specimen is shown in Fig. 5-8. The S-S curves for FEA were averaged by two material test curves.

$J_{Q}$ values were obtained from fracture toughness tests using $1 / 2$ TCT specimens. J-R curves were fitted by the equation $J=C_{l}(\Delta a)^{\mathrm{C} 2} . J_{Q}, C_{l}$ and $C_{2}$ are shown in Table 4. J-R curves of each material are shown in Fig. 9-12. The curve used for FEA was the lower of the two measured curves for each material.

Table 3 Tensile properties $\left(325^{\circ} \mathrm{C}\right)$

\begin{tabular}{cccccccc}
\hline Specimen & Material & $E(\mathrm{GPa})$ & Ferrite content $(\%)$ & Aged/Unaged & $\sigma_{y}(\mathrm{MPa})$ & $\sigma_{B}(\mathrm{MPa})$ & $\sigma_{f}(\mathrm{MPa})$ \\
\hline B1 & Base & & 9.3 & Aged & 148 & 429 & 289 \\
B2 & Base & 174.00 & 10.5 & Unaged & 155 & 406 & 280 \\
B4 & Base & & 18.9 & Aged & 190 & 547 & 369 \\
B5 & Weld & 174.56 & 18.9 & Aged & 348 & 500 & 424 \\
\hline
\end{tabular}

Table 4 Fracture toughness and fitting constants of J-R curve $\left(325^{\circ} \mathrm{C}\right)$

\begin{tabular}{ccccccc}
\hline Specimen & Material & Ferrite content $(\%)$ & Aged/Unaged & $J_{Q}\left(\mathrm{~kJ} / \mathrm{m}^{2}\right)$ & $C_{1}$ & $C_{2}$ \\
\hline C1 & Base & 9.3 & Aged & 243 & 334 & 0.667 \\
C2 & Base & 10.5 & Unaged & 509 & 480 & 0.575 \\
C4 & Base & 18.9 & Aged & 159 & 212 & 0.329 \\
C5 & Weld & 18.9 & Aged & 110 & 185 & 0.468 \\
\hline
\end{tabular}




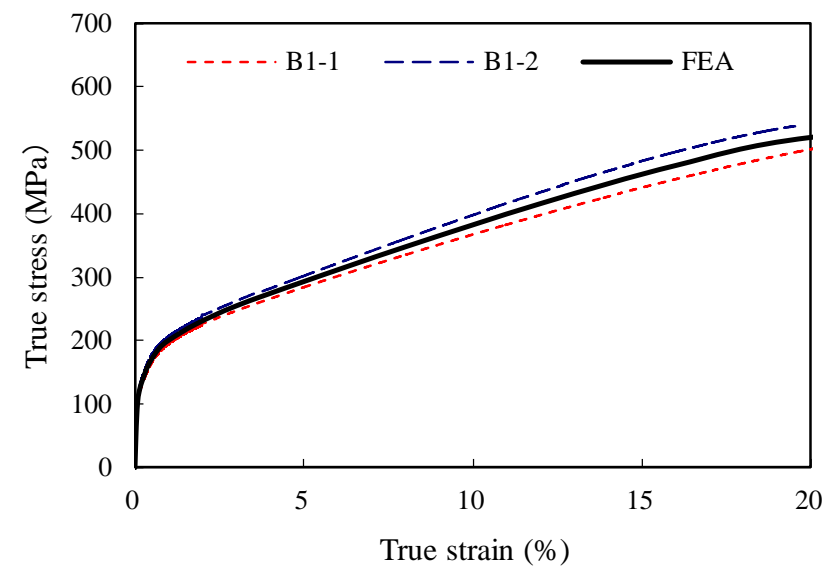

Fig. 5 S-S curve (Ferrite content 9.3\%, Aged A1-A4)

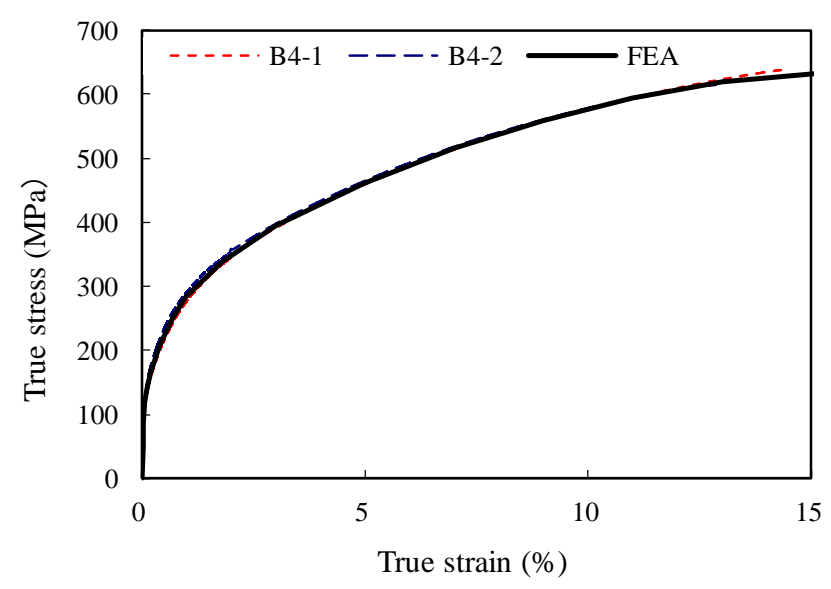

Fig. 7 S-S curve (Ferrite content 18.9\%, Aged A6 and A7)

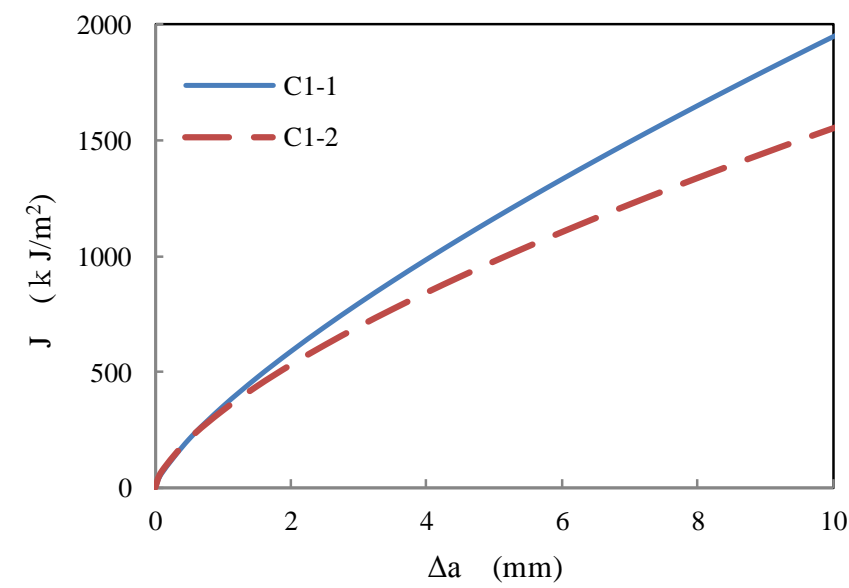

Fig. 9 J-R curve (Ferrite content 9.3\%, Aged A1- A4)

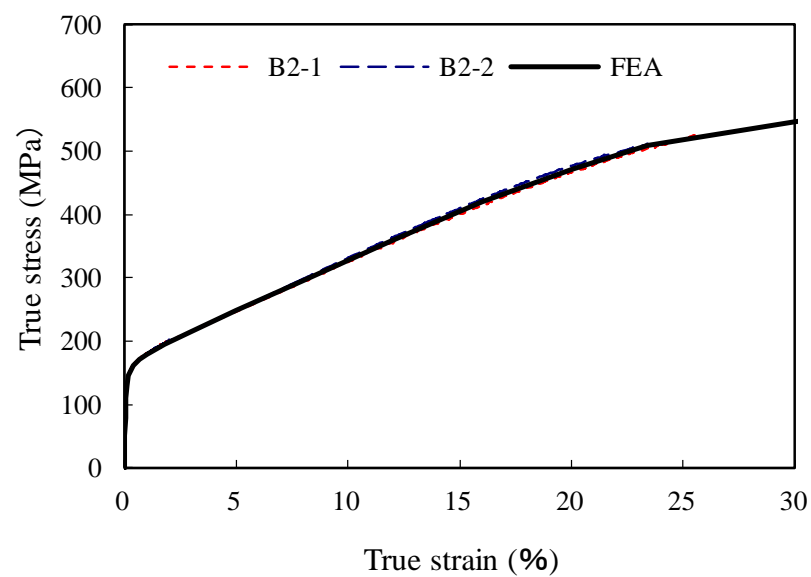

Fig. 6 S-S curve (Ferrite content 10.5\%, Unaged A5)

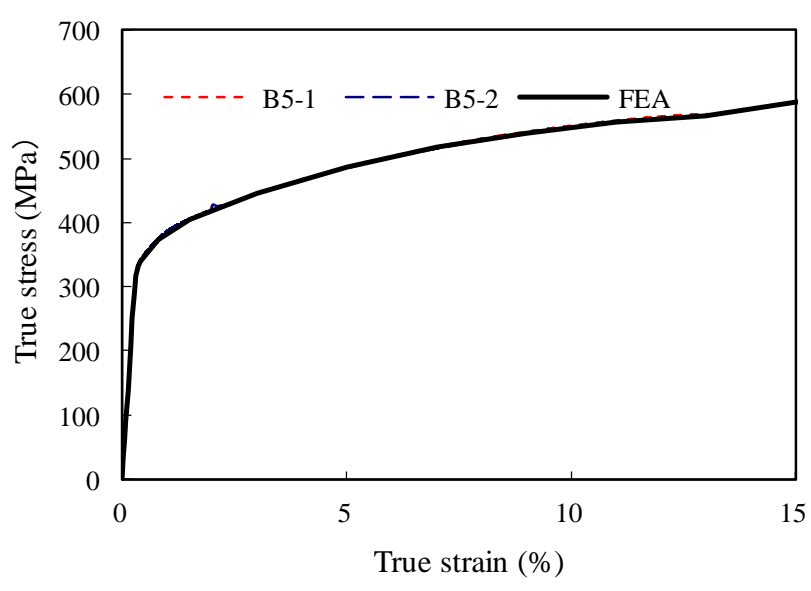

Fig. 8 S-S curve (Weld metal, Aged A7)

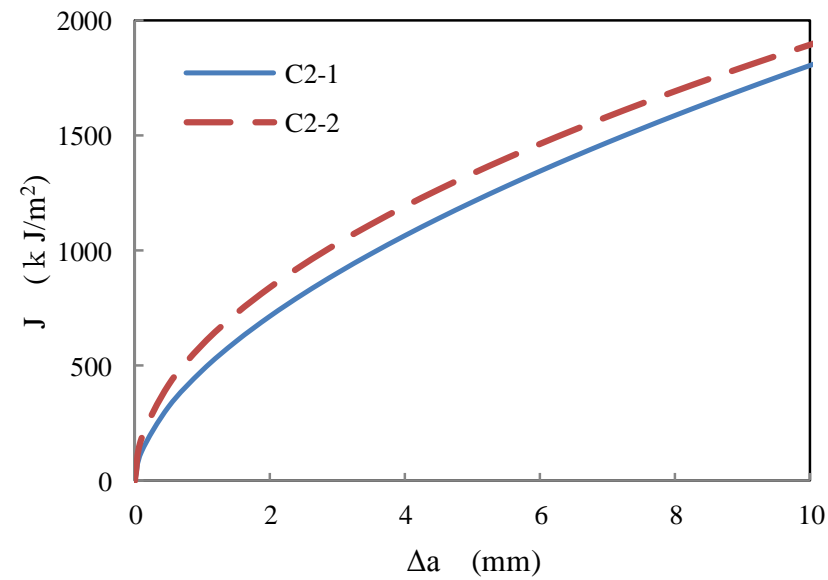

Fig . 10 J-R curve (Ferrite content $10.5 \%$, Unaged A5) 


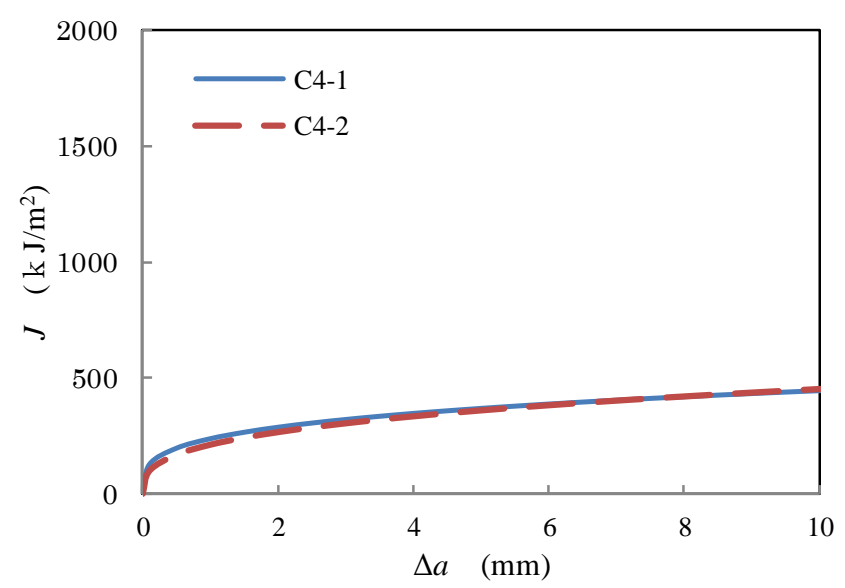

Fig. 11 J-R curve (Ferrite content 18.9\%, Aged A6 andA7)

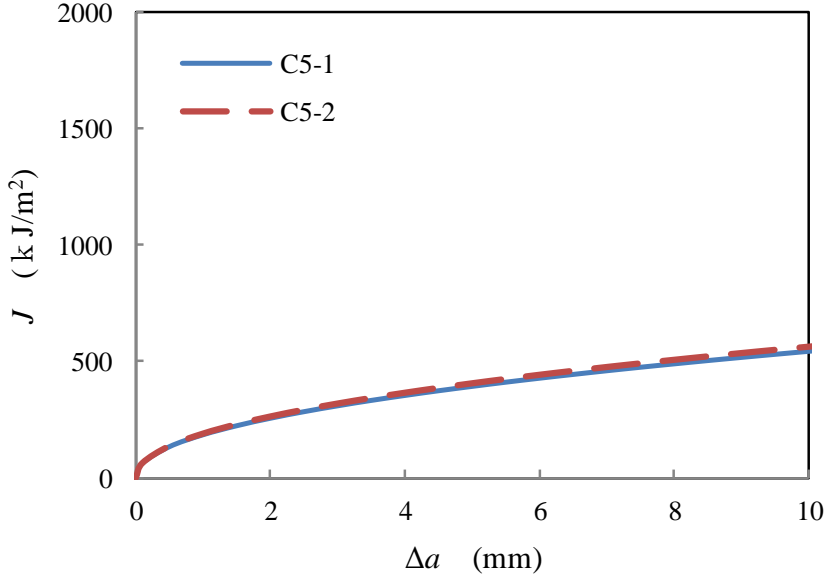

Fig. 12 J-R curve (Weld metal, Aged A7)

\section{(3) FE model}

Abaqus Ver. 6.8 was used for FEA. Figure 13 shows an example of an FE mode which is a quarter model due to symmetry. An FE model for the A6 specimen has 29,950 elements and 33,730 nodes. The element type is an eight node brick element. A pin was modeled using rigid elements, and tensile load was applied at the center of the pin. A tab was modeled with elastic elements.
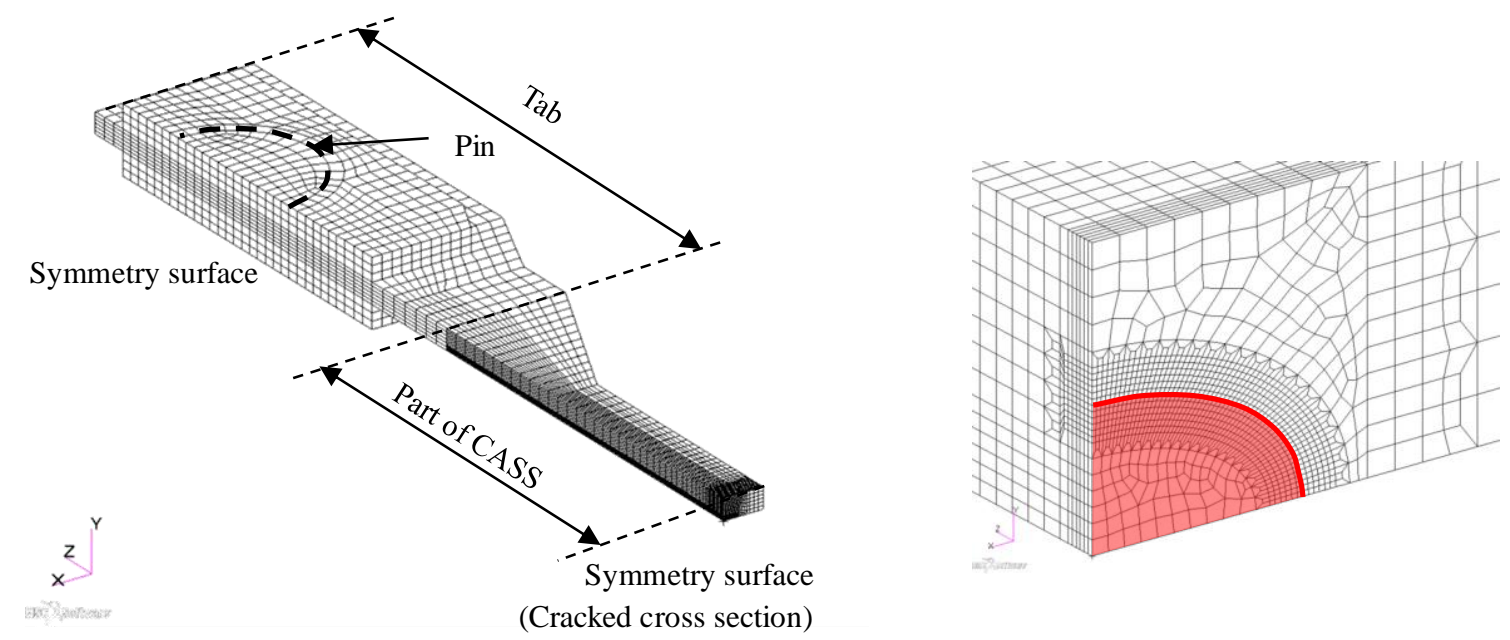

Fig. 13 FE model (A quarter symmetry, Specimen A6)

\subsubsection{Analysis result}

\section{(1) Critical fracture stress}

The critical fracture stress $\sigma_{c}$ was calculated with Eq. (4). Figure 14 shows the results based on ferrite content of base metal and weld metal. Rounded values $10 \%$ and $19 \%$ for ferrite content are used to express low values of $9.3 \%$, $10.5 \%$ and high values of $18.9 \%$. As shown in the figure, the critical fracture stress increases with decreasing flaw depth and increasing ferrite content. The maximum load or stress by the LL method was calculated using two kinds of criteria for flow stress and critical fracture stress. 


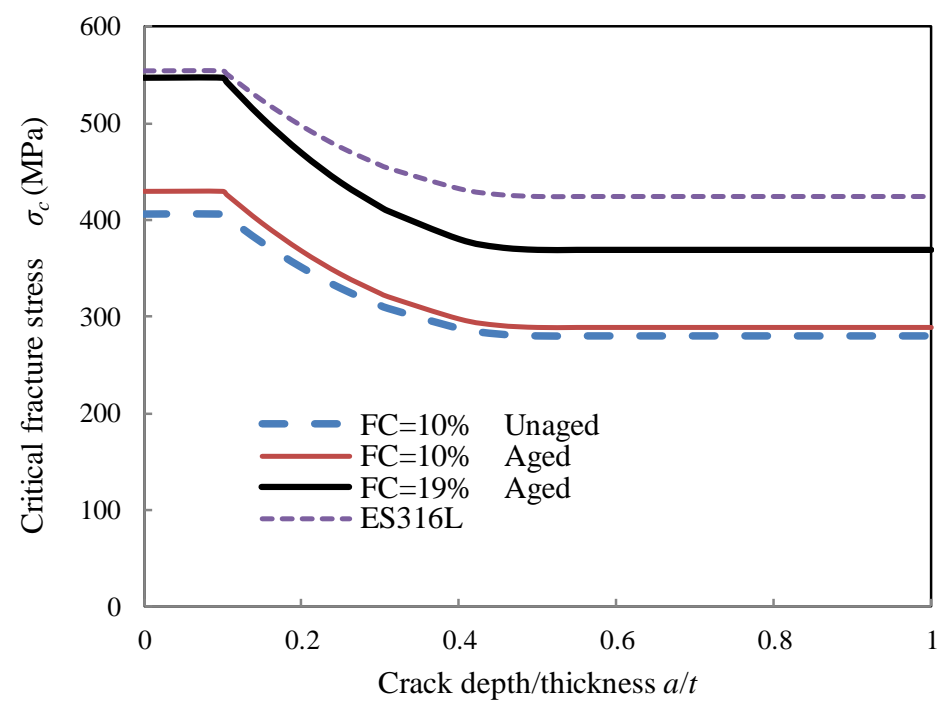

Fig. 14 Critical fracture stress-normalized crack depth relation

\section{(2) Comparison of ductile crack initiation load and maximum load of flat plate specimens}

Calculated load $P$-COD relations from FEA were compared with the measurement results. The curve for each specimen is shown in Fig. 15. The horizontal dotted lines show the maximum loads and the points indicate the ductile crack initiation by EPC method. Generally FEA can simulate the measured curves. The reason for the slightly larger discrepancy from early loading for curves A2 and A4 might be due to a larger scatter of the S-S curve for aged A1-A4 material, as shown in Fig. 5. Because material of A6 and A7 is aged CASS with high ferrite content, ductile crack growth occurs easily. The difference of the $P$-COD curves between FEA and the experiment near the maximum load of these specimens can be explained by this reason.

Table 5 shows the comparison of ductile crack initiation load between experiments and FEA. The measured load was determined by the EPC method. The calculated load was determined at the point where the calculated $J$ value was equal to $J_{Q}$ from Table 4. The ratios of the loads from experiment to those from FEA are 0.98-1.14 which shows relatively good coincidence except for specimen A5. The initiation point by the EPC method of the specimen A5 is not indicated because an inflexion point was not measured due to the cable coming off for the EPC measurement from the terminal. The difference between the results of experiments and the analyses of the other specimens may be caused by an error in EPC measurement, and the difference of the $J$ value at ductile crack initiation between a CT specimen and a flat plate from different constraints. This can be explained by the tendency of most ratios being larger than 1.0.

Figure 16 shows comparison of the predicted maximum stresses with the experiment data.

The maximum stress of the specimens A1 and A2 with low ferrite content and a shallow flaw can be predicted by the LL method using critical fracture stress $\sigma_{c}$. As the specimens A3 and A4 have low ferrite content with relatively deep flaws, the LL method with flow stress criterion $\sigma_{f}$ predicts the maximum load conservatively. For these specimens there is very little difference between the maximum loads of the two-parameters method and the LL method because the fracture mode was plastic collapse. The specimen A5 has the largest margin for the prediction load by the LL method. For the high ferrite content specimen A6, the LL method provides a small under-prediction, but the maximum stress by the two-parameters method agrees well with the experiment.

A7 is the weld joint specimen. The two-parameters method predicts the experimental result very well. A6 has the same geometry as A7. The measured maximum loads of both specimens are nearly equal and the loads by the two-parameters method predict the measurement conservatively and precisely without residual stress consideration. This means the effects of different weld metal properties between the base metal and weld metal, and the residual stress are negligibly small. 
Hojo, Ochi, Ogawa, Hayashi, Nishi and Yamane, Mechanical Engineering Journal, Vol.4, No.4 (2017)
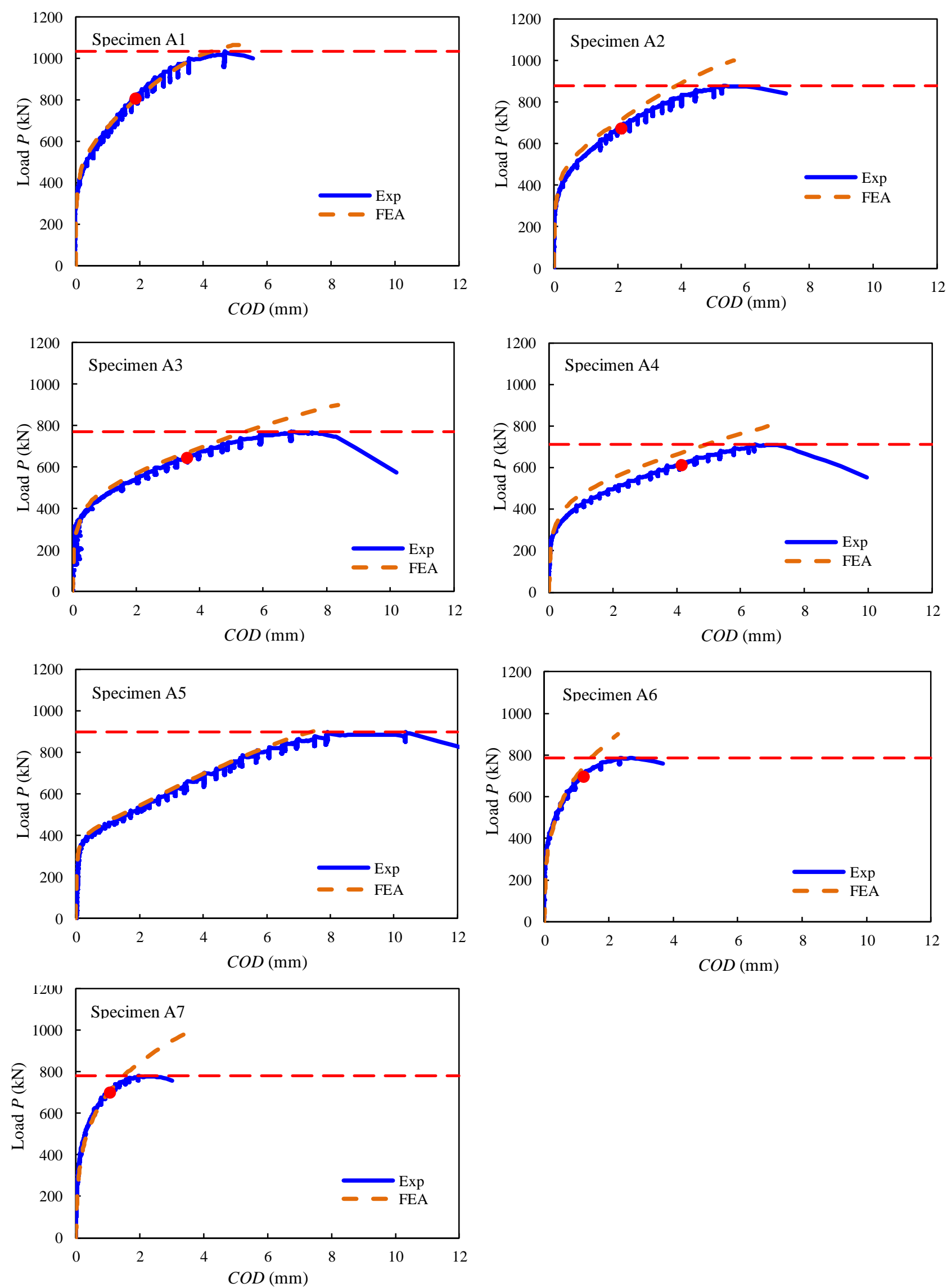

Fig. 15 Comparison between load-COD curves of experiment and FEA 
Table 5 Comparison of loads at ductile crack initiation between experiments and FEA

\begin{tabular}{|c|c|c|c|c|c|c|}
\hline \multirow{2}{*}{ Specimen } & \multirow{2}{*}{$\begin{array}{c}\text { Ferrite content } \\
\text { Material }\end{array}$} & \multicolumn{2}{|c|}{ Initial flaw } & \multicolumn{3}{|c|}{ Load at crack initiation $(\mathrm{kN})$} \\
\hline & & alt & a/l & Experiment & FEA & Exp/FEA \\
\hline A1 & & 0.096 & 0.064 & 799.4 & 815.9 & 0.98 \\
\hline $\mathrm{A} 2$ & $10 \%$ (Aged) & 0.22 & 0.15 & 692.9 & 659.6 & 1.05 \\
\hline A3 & Base metal & 0.48 & 0.33 & 640.4 & 567.3 & 1.13 \\
\hline A4 & & 0.68 & 0.59 & 625.6 & 591.9 & 1.06 \\
\hline A5 & $\begin{array}{c}10 \%(\text { Unaged }) \\
\text { Base metal }\end{array}$ & 0.30 & 0.19 & - & 713.0 & - \\
\hline A6 & $\begin{array}{l}19 \% \text { (Aged) } \\
\text { Base metal }\end{array}$ & 0.48 & 0.31 & 705.9 & 721.4 & 0.98 \\
\hline A7 & $\begin{array}{c}19 \%(\text { Aged) } \\
\text { Weld joint }\end{array}$ & 0.52 & 0.33 & 701.5 & $\begin{array}{l}702.3^{(1)} \\
617.0^{(2)}\end{array}$ & $\begin{array}{l}1.00 \\
1.14\end{array}$ \\
\hline
\end{tabular}

Note (1): the maximum $J$ in base metal, (2): $J$ at the deepest point of the flaw

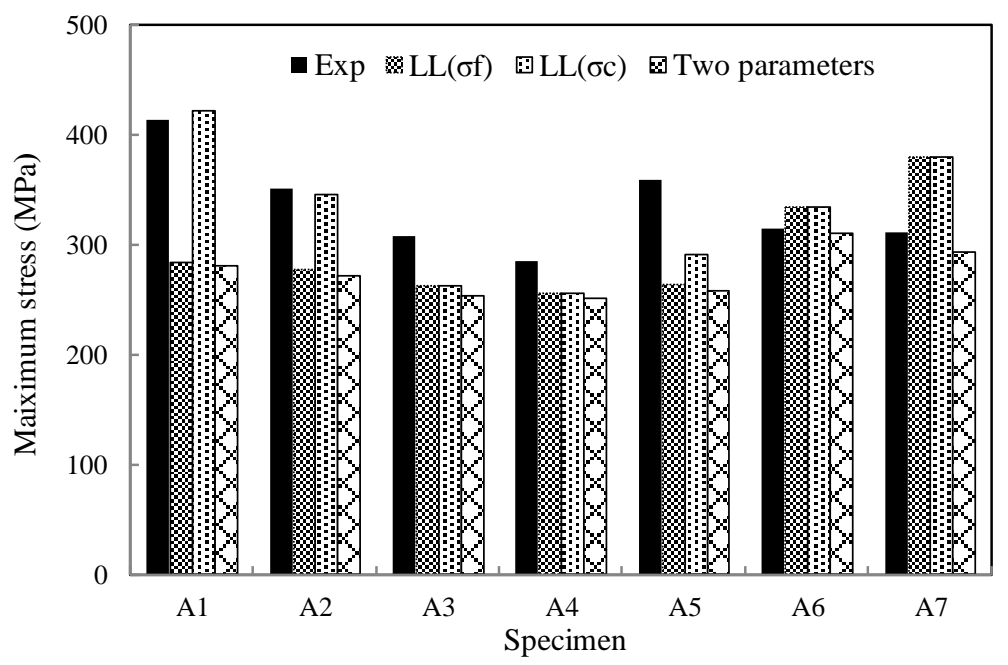

Fig. 16 Comparison of maximum stress by experiment and analysis

\section{(3) Screening criteria for selection of flaw evaluation corresponding to fracture mode}

ASME Sec. XI and JSME Rules on FFS have introduced the screening criteria (SC) to choose either the LL or the EPFM analysis method for ferritic piping since fracture toughness of ferritic pipes largely depends on its material. Fracture toughness of CASS also varies largely depending on ferrite content and aging condition, but the current version of the JSME rules does not apply SC to a CASS pipe.

EPRI Technical Report, 1988 describes that the value of SC (SC) which was defined by $K_{r}{ }^{\prime} / S_{r}{ }^{\prime}$ from the two-parameters method's calculation using a bent pipe with a fully circumferential flaw, or a pressurized pipe with a 2D axial flaw, for a specific material. The authors confirmed whether $S C$ is applicable to predict the failure mode of the fracture tests for the CASS flat plate specimens and a primary coolant pipe with an axial flaw. For $S C$ calculation of a flat plate, the same equations in section 2.3.1 (1) were used. SC of a pipe was calculated in accordance with the JSME rules.

Figure 17 shows the ratio of flaw depth to thickness a/t-SC relation for each model. The material of each pipe was assumed to be the same as the flat plate. From the results of Fig 16 and Fig. 17, only A7 of the flat plate specimens should be evaluated by the EPFM method. As shown in Fig. 16, the difference between the measured and predicted maximum stress by LL method in the case of the specimen A6 is 6\%, but that for A7 is nearly $20 \%$. Therefore 0.2 for $S C$ also appears to be a suitable value to choose for the evaluation method of CASS pipe. 


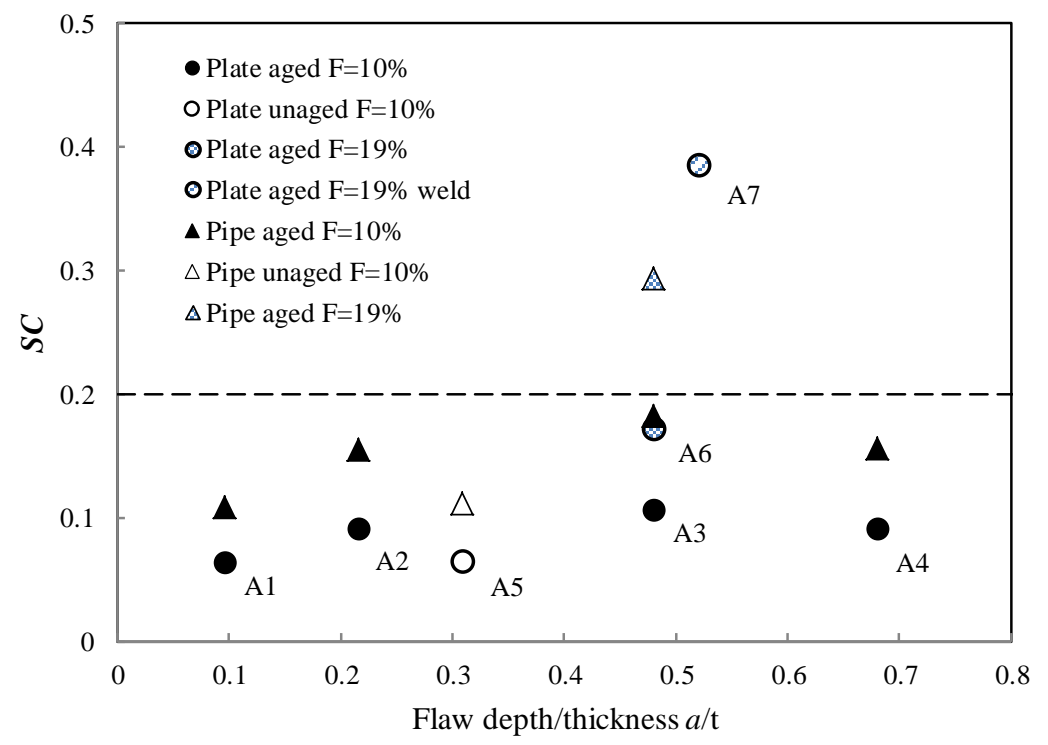

Fig. 17 SCs of the flat plate specimens and pipes

\section{Thermal aging model of $S-S$ curve and J-R curve for introduction to JSME rules 3.1 Revision of $S-S$ curve}

Kawaguchi et al.2005 developed prediction models for the S-S curve and J-R curve of CASS for thermal aging. His model focused on a relatively low strain region, less than $4 \%$ of total strain for R-O fitting. As a result, in higher strain regions, the predicted stress is lower than the actual stress. The stress level for fracture analysis generally exceeds the stresses corresponding to this strain region, and the analysis result may be too conservative. The authors revised the Kawaguchi's model to improve the prediction accuracy in higher strain region.

Aging condition and ferrite content strongly affect flow stress and yield stress. Kawaguchi chose $\left(\sigma_{y} / \sigma_{y 0}\right)$ and $\left(\sigma_{f}\right.$ $\left./ \sigma_{f 0}\right)$ as indices. For the revised model, flow stress was also chosen as an index for the prediction of S-S curves, and four $\mathrm{S}-\mathrm{S}$ curves were prepared as a database corresponding to the flow stress level. The categorized S-S curves at $325^{\circ} \mathrm{C}$ are shown in Table 6 and Fig. 18. Prediction flow is shown in Fig. 19 referring to Kawaguchi's model. Items 1-4 are the same as his model. Figure 20 shows the comparison of the measured and predicted stresses at the same strain for CASSs with different ferrite content. Data are within two times standard deviation.

\subsection{Verification of the revised model}

According to the flow, the predicted S-S curve of $10.5 \%$ ferrite CASS with aging condition of $400^{\circ} \mathrm{C}-60,000 \mathrm{hr}$ was obtained as one sample. Figure 21 shows the comparison between $\mathrm{S}-\mathrm{S}$ curves of the measured data, the original Kawaguchi's model, and the revised model. The revised model agrees better with the measured data than the original one. The revised model is recommended for the JSME rules.

For the J-R prediction model, the original Kawaguchi's model (H3T model) is to be applied to the JSME rules without revision. For the same material mentioned above, comparison of J-R curve from the prediction model and measurement is shown in Fig. 22, which shows good and conservative results compared with the prediction model.

Table 6 Predicted S-S curve by the revised model

\begin{tabular}{cccccccccc}
\hline \multirow{2}{*}{ Cat.1 } & \multirow{2}{*}{$\sigma_{f}=282 \mathrm{MPa}$} & $\varepsilon(\%)$ & 0.2 & 0.5 & 1 & 3 & 6 & 12 & 20 \\
& & $\sigma(\mathrm{MPa})$ & 134 & 166 & 185 & 227 & 274 & 366 & 473 \\
\hline \multirow{2}{*}{ Cat.2 } & \multirow{2}{*}{$\sigma_{f}=318 \mathrm{MPa}$} & $\varepsilon(\%)$ & 0.2 & 0.5 & 1 & 2 & 4 & 8 & 15 \\
& & $\sigma(\mathrm{MPa})$ & 149 & 192 & 222 & 254 & 297 & 371 & 484 \\
\hline \multirow{2}{*}{ Cat.3 } & \multirow{2}{*}{$\sigma_{f}=377 \mathrm{MPa}$} & $\varepsilon(\%)$ & 0.2 & 0.3 & 0.5 & 1 & 2 & 4 & 10 \\
& & $\sigma(\mathrm{MPa})$ & 178 & 204 & 235 & 269 & 308 & 360 & 487 \\
\hline \multirow{2}{*}{ Cat.4 } & \multirow{2}{*}{$\sigma_{f}=423 \mathrm{MPa}$} & $\varepsilon(\%)$ & 0.2 & 0.3 & 0.4 & 0.5 & 1 & 2 & 5 \\
& & $\sigma(\mathrm{MPa})$ & 182 & 211 & 235 & 255 & 315 & 365 & 462 \\
\hline
\end{tabular}




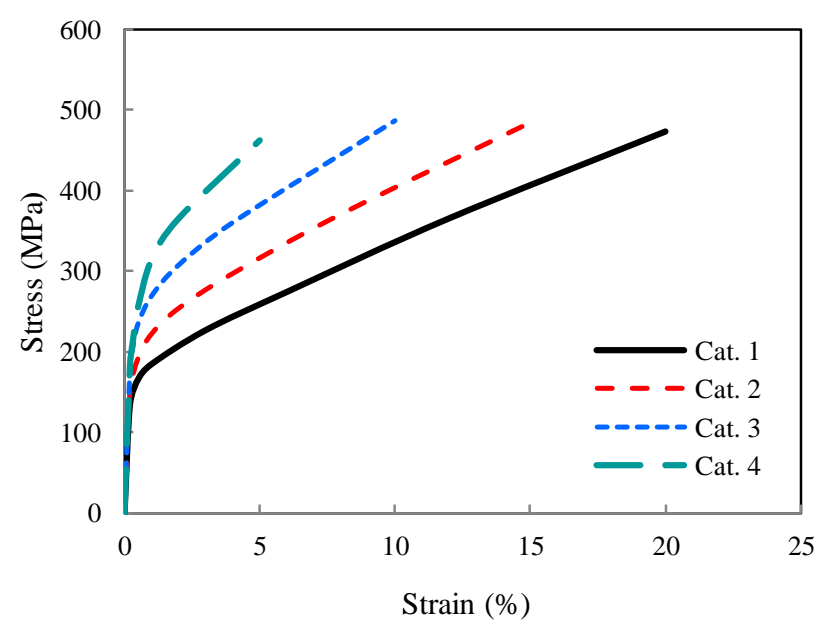

Fig. $18 \mathrm{~S}-\mathrm{S}$ curves for category $1-4\left(325^{\circ} \mathrm{C}\right)$

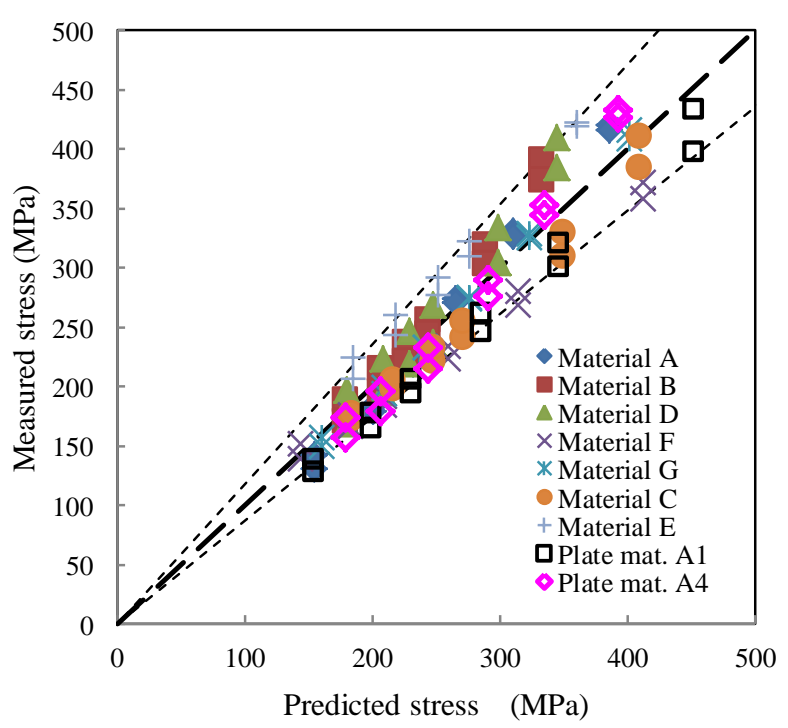

Fig. 20 Comparison of stresses of different materials $\left(400^{\circ} \mathrm{C}-60,000 \mathrm{~h}(\mathrm{~A}-\mathrm{E})\right.$, and $465^{\circ} \mathrm{C}-5,000 \mathrm{~h}$ (Plate $\mathrm{A} 1$ and $\left.\mathrm{A} 4\right)$ )

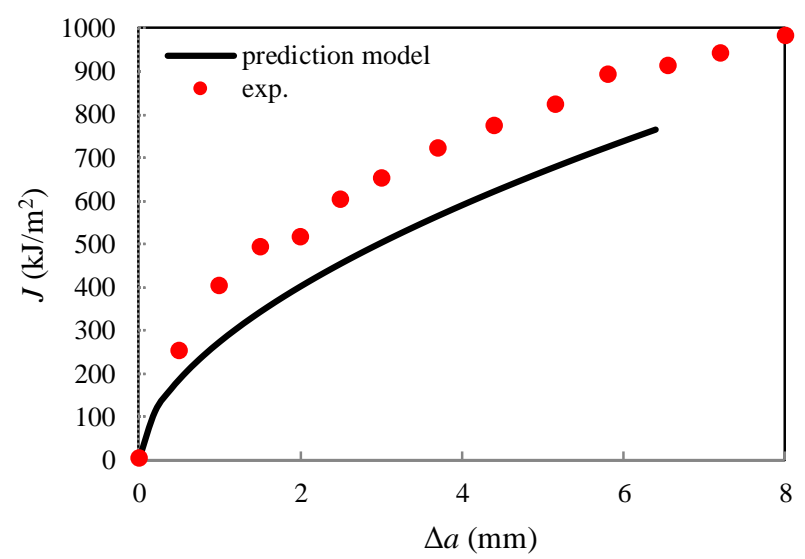

Fig. 22 Comparison of J-R curves of measured and prediction models $\left(325^{\circ} \mathrm{C}\right)$

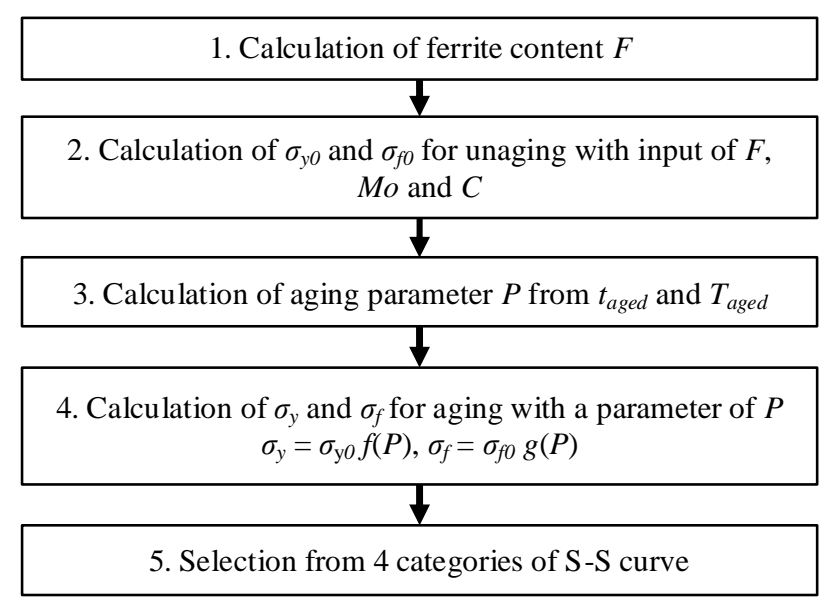

Fig. 19 Prediction flow of S-S curve for thermal aged CASS

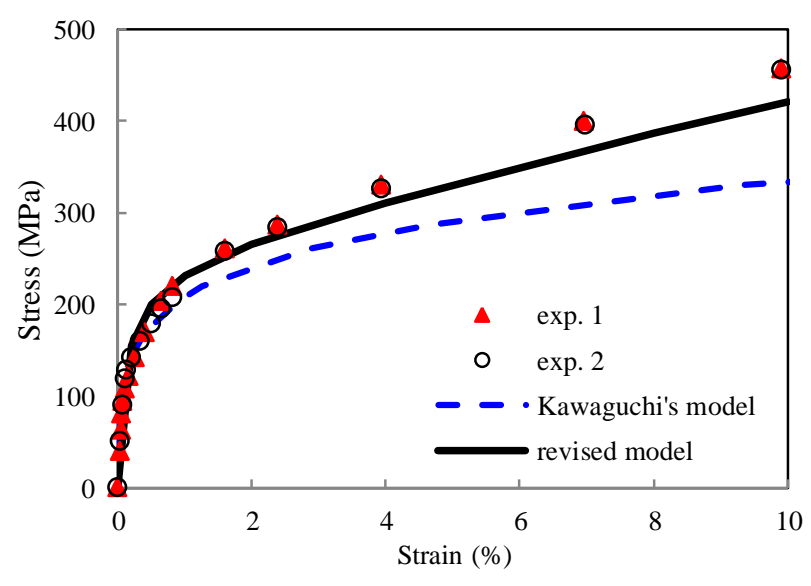

Fig. 21 Comparison of S-S curves of measured and prediction models $\left(325^{\circ} \mathrm{C}\right)$ 


\section{New Z-factor of a pipe with an axial surface flaw}

The JSME rules have introduced the Z-factor concept as the EPFM method for CASS, weld metal of SS and ferritic steel pipes. The current rules only include the Z-factor equations for a circumferential surface flaw. Kamaya et al. 2016 proposed Z-factor equations for these materials for pipes with an axial surface flaw. The authors verified its applicability for the equation of CASS pipes by comparing with the Z-factor derived from FEA.

\subsection{Analysis condition}

ASME Sec. XI or the JSME rules define Z-factor as a ratio of plastic collapse load (stress) to ductile instability load (stress). In order to obtain the ductile instability load, J-integral calculation is needed. The authors performed FEA to calculate $J$ and determined the ductile instability load by the two-parameters method. Abaqus Ver. 6.8 was the FE Code used.

(1) Material properties

Two material data from the flat plate specimens' and two materials from Kawaguchi et al. 2005 with fully aging condition were chosen. Table 7 shows the measured tensile properties and fracture toughness of each material. In Table $7 C_{1}$ and $C_{2}$ are the fitting constants for the J-R curve. Figure 23 and Fig. 24 show the S-S curves used for FEA and the $\mathrm{J}-\mathrm{R}$ curves used for the two-parameters method.

Table 7 Material properties for Z-factor calculation

\begin{tabular}{ccccccccc}
\hline \multirow{2}{*}{ Material } & \multirow{2}{*}{$\begin{array}{c}\text { Ferrite } \\
\text { content }(\%)\end{array}$} & \multirow{2}{*}{$\begin{array}{c}\text { Aging } \\
\text { condition }\end{array}$} & \multicolumn{2}{c}{ Tensile properties $(\mathrm{MPa})$} & \multicolumn{3}{c}{ Fracture toughness } \\
\cline { 5 - 9 } & 9.3 & $\sigma_{y}$ & $\sigma_{B}$ & $\sigma_{f}$ & $J_{Q}\left(\mathrm{~kJ} / \mathrm{m}^{2}\right)$ & $C_{1}$ & $C_{2}$ \\
\hline 1 & 18.9 & $5,000 \mathrm{~h}$ & 148 & 429 & 289 & 243 & 334 & 0.667 \\
2 & 17.4 & $400^{\circ} \mathrm{C}-$ & 220 & 643 & 431 & 218 & 271 & 0.316 \\
\hline 3 & 23.0 & $60,000 \mathrm{~h}$ & 256 & 722 & 489 & 90 & 108 & 0.200 \\
\hline
\end{tabular}

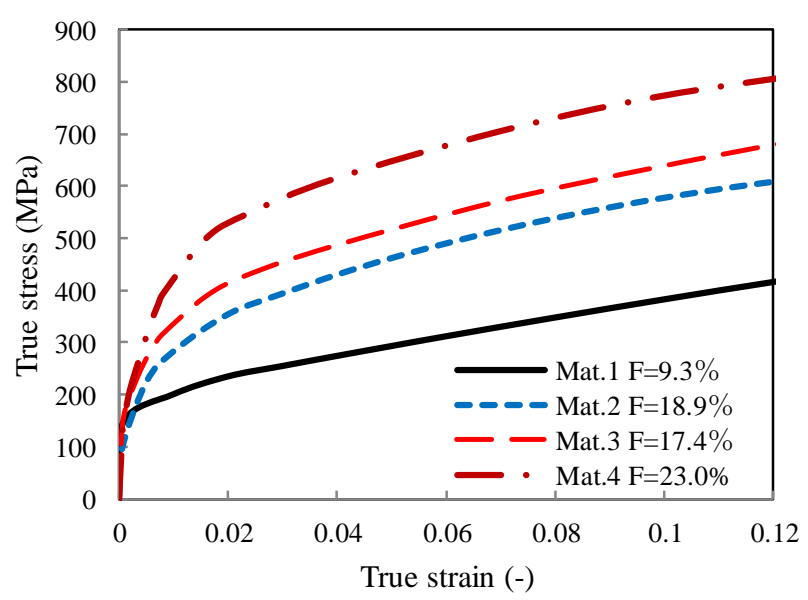

Fig. 23 S-S curves for FEA

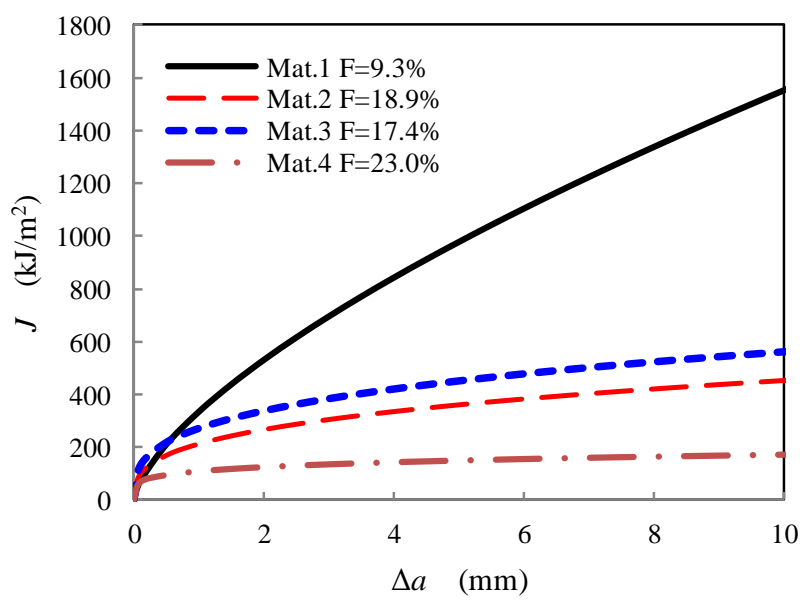

Fig. 24 J-R curves for two-parameters method

\section{(2) FE model}

Focused model was a primary coolant pipe of PWR. The outer diameter $D_{o}$ was $882.0 \mathrm{~mm}$ and thickness $t$ was $72.7 \mathrm{~mm}$. Figure 25 shows a quarter symmetrical FE model with an axial flaw and one example of a detailed figure for a flawed section. Pressure was applied to the inner surface and equivalent axial load was applied at the end of the nominal cross section, which was kept in plain constraint. The element type was a 20 node brick element and the numbers of elements and nodes were 34,730 and 164,900 , respectively. 

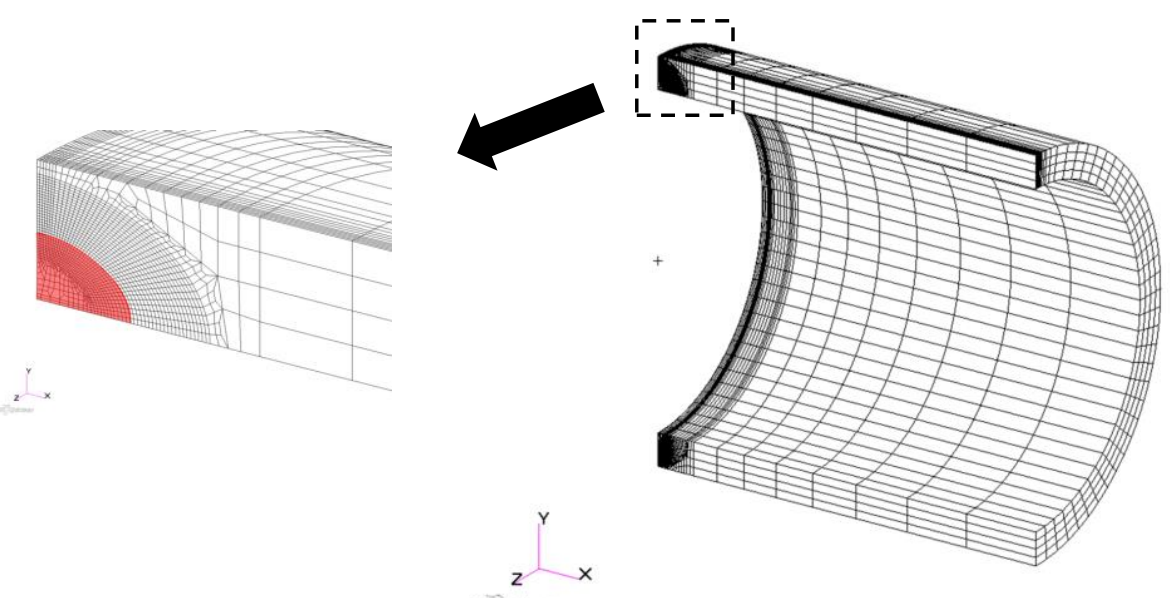

Fig. 25 FE model for Z-calculation

(3) Calculation of fracture pressure

FAC was drawn by calculating $S_{r}$ and $K_{r}$ with a parameter $p$ and by fixing the initial flaw shape.

$$
\begin{aligned}
& S_{r}=\frac{p}{p_{0}} \\
& K_{r}=\sqrt{\frac{J_{e}}{J}}
\end{aligned}
$$

Here $p_{0}$ is the plastic collapse pressure with $\sigma_{y}$ provided by Appendix E-10 of the JSME rules. The equations are shown below.

$$
\begin{aligned}
& p_{0}=\frac{2 t}{\sqrt{3} R_{i}}\left(1-\frac{a}{t}+\frac{a / t}{f(z)}\right) \sigma_{y} \\
& f(z)=\sqrt{1+1.61 z} \\
& z=\frac{0.1542^{2}}{a t\left(R_{i} / t+0.5\right)}
\end{aligned}
$$

To avoid additional conservatism, $R_{\mathrm{i}}$ was replaced by $R_{a v}$ for the calculation. The cut off was defined by $S_{r}=p_{f} / p_{0}$. $p_{f}$ is the plastic collapse pressure with $\sigma_{f}$.

The DCGL was drawn by calculating $S_{r}$, and $K_{r}$ ' with a parameter flaw depth $a$ and fixed pressure. The equations for $S_{r}{ }^{\prime}$ and $K_{r}$ ' are the same as those of $S_{r}$ and $K_{r}$. The maximum flaw depth was $0.75 t$.

(4) Analysis case

Table 8 shows the analysis cases. The flaw shapes were selected considering those of the flat plate specimens.

Table 8 Analysis case

\begin{tabular}{cccc}
\hline \hline \multirow{2}{*}{ Case } & Material number & \multicolumn{2}{c}{ Flaw shape } \\
\cline { 3 - 4 } & ferrite content $(\%))$ & $a / t$ & $a / l$ \\
\hline 1 & $1(9.3)$ & 0.48 & 0.330 \\
2 & $2(18.9)$ & 0.48 & 0.313 \\
3 & $3(17.4)$ & 0.75 & 0.5 \\
4 & $4(23.0)$ & 0.75 & 0.25 \\
5 & $4(23.0)$ & 0.50 & 0.333 \\
6 & $4(23.0)$ & 0.25 & 0.167 \\
\hline
\end{tabular}




\subsection{Analysis result}

Figure 26 shows the FADs of Case 1 and Case 5 as examples. Case 1 is for low ferrite content and Case 5 for high content. As shown in these figures, the fracture mode of Case 1 is plastic collapse, and that of Case 2 is ductile fracture.
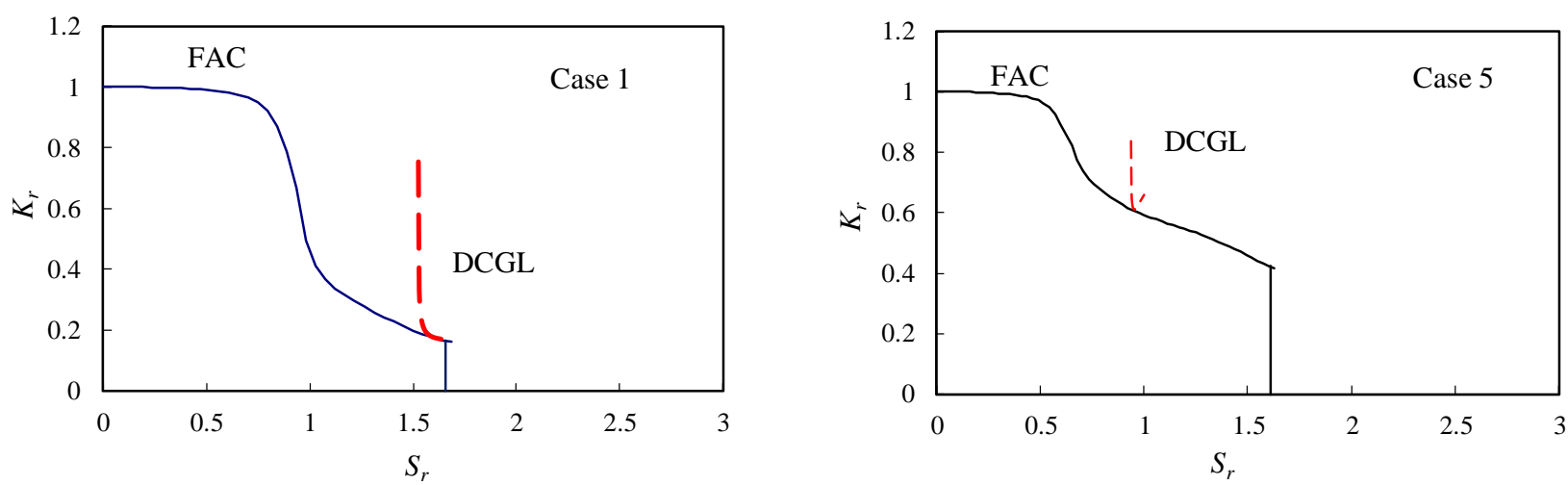

Fig. 26 FAD for primary coolant pipe

Figure 27 shows the comparison between Z-factors obtained by FEA and the equation proposed by Kamaya et al. , 2016. The equation for CASS is shown below. This equation was derived by the combination of fully aged J-R curve and unaged S-S curve with ferrite content $23 \%$ of CASS.

$$
Z=-3.0\left(\frac{a}{t}-0.4-5.0 \times 10^{-5} D_{o}\right)^{2}+0.7\left(D_{o}\right)^{0.121}
$$

Except for Case 4, the proposed Z-factors are nearly equal to or larger than those from FEA. As Case 1 is for low ferrite number, the fracture mode is plastic collapse. In Fig. 26, DCGL contacts the tail of FAC, meaning FEA also estimates plastic collapse fracture mode. However, since Eq. (14) only has parameters $D_{\mathrm{o}}$ and $a / t$, a large Z-factor was estimated in Case1. For Case 3, due to a very large alt, the difference between both Z-factors becomes smaller. Since the condition of Case 4 is the application limit of flaw size and ferrite content, the prediction seems on unconservative side. As a result, the Z-factor's equation has a large enough margin if the ferrite number is less than $20 \%$, and it is confirmed that the equation is applicable to CASS pipes. In order to reduce unnecessary margin, direct analysis is recommended to calculate the Z-factor using the S-S and J-R curves with the prediction models described in Chapter 3.

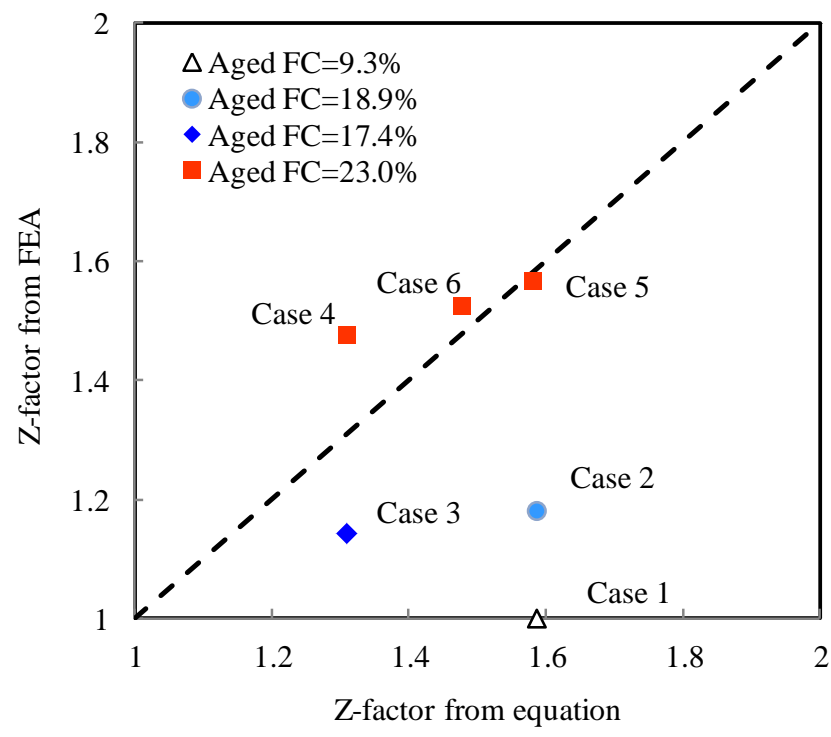

Fig. 27 Comparison between Z-factors from FEA and equation 


\section{Conclusions}

In order to revise the JSME rules on fracture analysis method for CASS pipe, the followings were investigated and confirmed.

- The fracture tests using tensile flat plate specimens with a surface flaw showed that an unaged or aged low ferrite specimen fractured by plastic collapse.

- Critical fracture stress $\sigma_{c}$ for plastic collapse can be applied to not only a ferrite pipe but also a CASS pipe.

- Thermal aging has a large effect in the case of large ferrite content. The J-R curve becomes lower and the S-S curve becomes higher. This compensates maximum load on the fracture behavior. The test results of the flat plate specimens show very small difference between high and low ferrite content, and unaged and aged conditions.

- Therefore if the thermal aging prediction model is introduced, the models have to be considered not only for J-R curves, but also for $\mathrm{S}-\mathrm{S}$ curves.

- The S-S prediction model was revised from the original Kawaguchi's model, and improvement of prediction accuracy was verified.

- The Z-factor for an axial flaw proposed by Kamaya is applicable to CASS pipe by applying an FEA model of a primary coolant pipe with a very large margin for ferrite content less than $20 \%$.

- The knowledge from this research is to be reflected in the revision of the JSME rules on FFS for the fracture analysis method of CASS pipe.

\section{Acknowledgement}

The research was funded by PWR owners group. The authors express acknowledgments to The Kansai Electric Power Co., Hokkaido Electric Power Co., Shikoku Electric Power Co., Kyushu Electric Power Co., and The Japan Atomic Power Co. Also the authors thank Dr. Masayuki Kamaya for technical advice.

\section{References}

Ainsworth, R. A., Milne, I., Dowling, A. R., and Stewart, A. T., Assessing the integrity of structures containing defects by the failure assessment diagram approach of the CEGB (1986), In Fatigue and fracture assessment by analysis and testing.

ASME Boiler \& Pressure Vessel Code Section XI Rules for Inservice Inspection of Nuclear Power Plant Components 2015 Edition (2015), The American Society of Mechanical Engineers.

Code Case for Nuclear Power Generation Facilities - Rules on Fitness-for-Service for Nuclear Power Plants, Flow Stress using Limit Load Evaluation Method NA-CC-010 (2013), The Japan Society of Mechanical Engineers (in Japanese).

Codes for Nuclear Power Generation Facilities - Rules on Fitness-for-Service for Nuclear Power Plants - JSME S NA1-2012 (2012), The Japan Society of Mechanical Engineers (in Japanese).

Hojo, K. and Koyama, K., Derivation Condition of Z-Factor for Austenitic Stainless Steel Pipe of JSME Rules on fitness-for-service for Nuclear Power Plants, Proceedings of M\&M Material Mechanics Conference 2009 (2009), Paper No. OS1403 (in Japanese).

Hojo, K., Nishi, W. and Hayashi S., CASS FRACTURE TESTS USING FLAT PLATE SPECIMENS WITH A SURFACE FLAW, Proceedings of the ASME 2015 Pressure Vessels \& Piping Conference (PVP2015) (2015), Paper No. PVP2015-45325.

Kamaya, M., Machida, H., Itatani, M. and Hojo, K., Z-factor equations for elastic-plastic fracture mechanics analysis prescribed in the JSME rules on fitness-for-service for nuclear power plants, Transactions of the JSME (in Japanese), Vol. 82, No. 841 (2016), DOI: 10.1299/transjsme.16-00263.

Kawaguchi, S., Nagasaki, T. and Koyama, K., PREDICTION METHOD OF TENSILE PROPERTIES AND FRACTURE TOUGHNESS OF THERMALLY AGED CAST DUPLEX STAINLESS STEEL PIPING, Proceedings of the ASME 2005 Pressure Vessels \& Piping Conference (PVP2005) (2005), Paper No. PVP2005-71528.

Koyama, K., Hojo, K., Muroya, I. and Kawaguchi, S, Z factors for Aged Cast Duplex Stainless Steel Pipes and Welds, Proceedings of the 7th International Conference on Nuclear Engineering (ICONE-7) (1999), Paper No. ICONE-7477.

Kumar, V., M., German, D. and Shih, C. F., Engineering approach for elastic-plastic fracture analysis. EPRI-NP-1931 
(1981), Electric Power Research Institute.

Norris, D. M., Evaluation of Flaws in Ferritic Piping, EPRI NP-6045 (1988), Electric Power Research Institute.

Sattari-Far, I. and Dillström, P., Local limit load solutions for surface cracks in plates and cylinders using finite element analysis, International journal of pressure vessels and piping, Vol. 81, No.1 (2004), pp. 57-66.

Wilkowski, Gery M., and Scott, P. M., A statistical based circumferentially cracked pipe fracture mechanics analysis for design or code implementation, Nuclear engineering and design 111.1 (1989), 173-187. 